uniform in all directions, or is small compared with the surface-tension. This tension is merely a convenient way of expressing the resultant effect of the mutual attractions between the molecules upon the envelope. The curious myelin forms developed when certain fatty substances are dissolved in water are an interesting illustration of this phenomenon. It has recently been discovered that, while the interior is isotropic, the envelope is liquid-crystalline, and that the typical marrow-like shape results from the preponderance of the latter; the contour is circular when the envelope is thin. It was with some hesitation that Prof. Lehmann proposed the extended signification of the word crystal; it is, however, difficult to suggest an alternative, and, etymologically at least, a good claim may be made out for its use to denote the fluid form.

That crystals, when placed in the saturated mother liquor, grow and have the power of healing fractures are characteristics so similar to the attributes of certain of the lower organisms that they suggest the possibility of crystallised matter being a form of life; but a little consideration raises insuperable objections to such a theory. Prof. Lehmann's researches, however, throw fresh light upon the problem, and he ventures with some confidence to assert, not that crystals themselves are living, but that crystallisation is the agency made use of by living growth. A glass or jelly, or any other amorphous substance, does not grow; on cooling it passes gradually from the melted to the solid condition, and forms about a large number of nuclei, just as happens in the condensation of vapour. Crystallisation is a very different phenomenon; the growth is rapid and the nuclei are comparatively few. The distinction consists in the want of homogeneity of an amorphous substance, which results in the neutralisation of the intermolecular action. In such a substance doubtless several arrangements of the constituent parts are possible for equilibrium, and though there may be uniformity over a not inconsiderable region-judged by molecular dimensions-the resultant effect is chaos. Prof. Lehmann noticed further that liquid crystals, when under the influence of a magnetic field, coalesce and range themselves with their axes in the direction of the lines of force; in other words, the growth of an individual takes place. In fact, the similarity in aspect and behaviour between certain liquid crystals and bacteria is remarkable, and can scarcely be accidental. Prof. Lehmann suggests that in life the directional force is that mysterious essence so much discussed and so little understood-the soul. In support of this bold hypothesis he puts forward many cogent arguments and marshals an array of facts, but much work and consideration are necessary before it can be accepted with any confidence. Nevertheless, it must be admitted that Prof. Lehmann has made an important contribution to the solution of the great question confronting alike science and philosophywhat is life?

$$
\text { G. F. H. S. }
$$

\section{METEOROLOGICAL REPORTS BY WIRELESS} TELEGRAPHY.

THE British Meteorological Office is making arrangements in conjunction with the Deutsche Seewarte, Hamburg, for an experiment in the transmission of meteorological reports by wireless telegraphy. The intention is to make an experiment extending over a period of three months. It was anticipated that arrangements would be concluded in time for commencement with the New Year. It has been found necessary, however, to postpone the actual experiment until February. In the meantime the pre- parations for the transmission to the Meteorological Office of reports from the ships of the Allan, Ameri. can, Anchor, Atlantic Transport, Canadian Pacific, Cunard, Dominion, Red Star, and White Star lines have been completed, so far as they can be without trial, and the agents of the Marconi Company in London have already notified their officials to proceed from January $\mathrm{I}$.

There are many points as to instruments and other matters likely to arise which can only be solved by experience, and the position for effective cooperation will be improved by a trial of the arrangements in view. With this object, instructions as to observations and forwarding the information have been sent to the lines which are so courteously aiding this experiment, and full advantage is being taken to secure observations at once, and to avoid the loss of information for so important a month as January. Wireless telegrams. from ships in different parts of the Atlantic may be expected now at any time. The disturbances which exert such an important influence on our weather, especially in the winter, arrive almost without exception from the Atlantic, and it is believed that observations showing the movements of these disturbances will materially add to our knowledge of the weather changes, and aid in weather forecasting.

\section{THE ITALIAN EARTHQUAKE.}

NEVER had earthquake taken such toll of human life as that which has just devastated Calabria. Hundreds had been killed by a single earthquake, or thousands, exceptionally the number had run to tens of thousands, but the Yeddo-now Tokio-earthquake of 1703 , with its death-roll of 200,000 , had stood in a class by itself; yet even this great number seems insufficient to count the deaths on the morning of December 28, I908, and if to those whose lives were ended by the immediate effects of the earthquake we add the subsequent deaths from injury, exposure, and sickness, the loss will amount to well over a quarter of a million lives.

In face of such a disaster humanity, staggered at first, has thought of nothing but relief or palliation, and the daily newspapers, filled with accounts of destruction, misery and rescue, have contained little information from which we can form a proper judgment of the nature of the shock or its magnitude. This much, however, is clear, that the earthquake was of the first order, not so great, perhaps, as the Californian or Chilian earthquakes of I906, but far greater than the Calabrian ones of 1905 and 1907 , and as great as either of the celebrated earthquakes in $178_{3}$, which caused 40,000 deaths in the same districts as have just suffered an even greater loss of life.

From Pizzo the band of destruction extends southwards for about 50 miles through ill-starred Monteleone, which no earthquake seems to spare, Palmi, and Bagnara, to Reggio di Calabria. In Sicily. Messina has been destroyed, and Gazzi, but except from this narrow strip of country we have few reports. Catanzaro. suffered, to what extent does not appear, and at Cosenza the damage was great; in Sicily houses were destroyed in San Filippo, near Milazzo, and many were damaged in Caltanisetta and Noto, yet Catania escaped uninjured, and at Taormina only one building is said to have suffered any injury. The shock was felt, though slight, at Brindisi and Taranto, at Naples and Castellamare, and at Palermo the population fled in terror into the streets, though no damage was done.

From the interior of Aspromonte no news has come as yet, but the scanty information, summarised above, is enough to show that this earthquake, like most of those in Calabria and Sicily, was polycentric, originat- 